\title{
Clinical outcome and risk factors related to extended-spectrum beta-lactamase-producing Kebsiella spp. infection among hospitalized patients
}

\author{
Fernando Bellíssimo-Rodrigues/ ${ }^{+}$, Ana Carolina Frade Gomes*, \\ Afonso Dinis Costa Passos**, Jorge Alberto Achcar**, Gleici da Silva Castro Perdoná**, \\ Roberto Martinez***
}

\author{
Comisão de Controle de Infecção Hospitalar *Laboratório de Microbiologia **Departamento de Medicina Social \\ ***Departamento de Clínica Médica, Hospital das Clínicas, Faculdade de Medicina de Ribeirão Preto, Universidade de São Paulo, \\ Av. dos Bandeirantes 3900, 14048-900 Ribeirão Preto, SP, Brasil
}

\begin{abstract}
Over the past two decades, nosocomial infections caused by extended-spectrum beta-lactamase (ESBL)-producing Klebsiella spp. have become a major problem all around the world. This situation is of concern because there are limited antimicrobial options to treat patients infected with these pathogens, and also because this kind of resistance can spread to a wide variety of Gram-negative bacilli. Our objectives were to evaluate among in-patients at a public university tertiary-care hospital with documented infection due to Klebsiella spp., which were the risk factors (cross-sectional analysis) and the clinical impact (prospective cohort) associated with an ESBL-producing strain. Study subjects were all patients admitted at the study hospital between April 2002 and October 2003, with a clinically and microbiologically confirmed infection caused by Klebsiella spp. at any body site, except infections restricted to the urinary tract. Of the 104 patients studied, 47 were infected with an ESBL-producing strain and 57 with a non-ESBL-producing strain. Independent risk factors associated with infection with an ESBL-producing strain were young age, exposure to mechanical ventilation, central venous catheter, use of any antimicrobial agent, and particularly use of a 4th generation cephalosporin or a quinolone. Length of stay was significant longer for patients infected with ESBL-producing strains than for those infected with non-ESBL-producing strains, although fatality rate was not significantly affected by ESBL-production in this cohort. In fact, mechanical ventilation and bacteremia were the only variables with independent association with death detected in this investigation.
\end{abstract}

Keywords: extended-spectrum beta-lactamase - Klebsiella spp. - risk factors - clinical outcome

Over the past two decades, nosocomial infections caused by extended-spectrum beta-lactamase (ESBL)-producing Klebsiella spp. have become a major problem all around the world (CDC 1998, Archibald 2004, Martins et al. 2005). This situation is of concern because there are limited antimicrobial options to treat patients infected with these pathogens (Bratu et al. 2005), and also because this kind of resistance can spread to a wide variety of Gramnegative bacilli, either Enterobacteriaceae (Knothe et al. 1983, Chanawong et al. 2001, Petroni et al. 2002, Calatayud 2005) or non-fermentative microorganisms (Poirel et al. 2003, Quinteros et al. 2003).

Several risk factors for ESBL-producing Klebsiella spp. infections have been described, the most frequent being antimicrobial exposure, especially to third-generation cephalosporins (Naumovski et al. 1992, Lautenbach et al. 2001, Bermejo et al. 2003, Lee et al. 2004), and exposure to invasive procedures such as central venous catheters, mechanical ventilation, urinary catheterization and intraabdominal surgery (Piroth et al. 1998, Lautenbach et al. 2001, Menashe et al. 2001).

\footnotetext{
Financial support: Faepa-USP

${ }^{+}$Corresponding author: fbellissimo@ig.com.br

Received 6 February 2006

Accepted 5 May 2006
}

It has also been demonstrated that this kind of infection increases length of stay among hospitalized patients (Cofsky et al. 2002, Stone et al. 2003), producing a significant economic impact (Stone et al. 2003).

The literature is conflictive about the effect on mortality caused by ESBL-producing Klebsiella spp. compared to non-ESBL-producing Klebsiella spp., with some studies reporting a negative impact (Paterson et al. 1997, Kim et al. 2002, Bermejo et al. 2003, Martínez et al. 2005) and others finding no impact (Menashe et al. 2001, Kang et al. 2004).

The purpose of the present study was to assess the risk factors and clinical impact associated with ESBL-producing strains, compared to non-ESBL-producing strains among in-patients at a university hospital with documented infection caused by Klebsiella spp.

\section{MATERIALS AND METHODS}

The University Hospital of the Faculty of Medicine of Ribeirão Preto (HC-FMRP) is a general hospital located in Ribeirão Preto city, at the state of São Paulo. It has 847bes, distributed in 29 wards with several clinical and surgical specialties. It has six intensive-care units, being their areas of activities: neonatology, pediatry, general care of adults, cardiology, thoracic surgery, and neurosurgery.

The research project was submitted to the local Ethics Committee and was approved. Between April 2002 and October 2003, we investigated every strain of Klebsiella 
spp. isolated on the microbiology laboratory of the study hospital in order to identify potential eligible patients. Study population consisted of all patients admitted, with a clinically and microbiologically confirmed infection caused by Klebsiella spp. at any body site, except infections restricted to the urinary tract. Some patients who had bacteremia and urinary tract infection caused by the same agent were included.

The bacterial strains were identified using the MicroScan ${ }^{\circledR} 2$ NC30 panel (Dade, West Sacramento, California, US). Susceptibility to antimicrobial agents was determined using a semiautomated system (MicroScan ${ }^{\circledR}$ 2, NC30 panel) or disk-diffusion susceptibility testing, according to the criteria of the Clinical Laboratory Standards Institute (formerly National Committee for Clinical Laboratory Standards- NCCLS 2000). All isolates of Klebsiella spp. were submitted to ESBL detection tests by by the E-test ${ }^{\circledR}$, with ceftazidime and cefotaxime, each alone or combined with clavulanic acid, in order to obtain a more sensitive detection (M'zali et al. 2000, Quinteros et al. 2003). We considered the E-test ${ }^{\circledR}$ to be positive when it showed at least a 4-fold decrease in the MIC for the combination side, compared to the cephalosporin alone side (NCCLS 2000). Strains were considered to be ESBL-producers when they tested positive in at least one detection test. K. pneumoniae ATCC 700603 was used as a positive control and E. coli ATCC 25922 as a negative control for the ESBL detection tests.

Clinical data were collected from the medical records and also from physical examination of the patients, always by the same researcher. To establish a diagnosis of infection we used CDC definitions for nosocomial infections (Garner et al. 1988). We excluded patients whose bacteria lost viability, leading to unavailable tests for ESBL detection. We collected demographic and clinical data like sex, age, date of admission, date of infection diagnosis and date of discharge. We also looked for underlying diseases, exposure to invasive procedures, corticosteroids and other immunosuppressive therapies within two weeks before the diagnosis of infection. Corticosteroid use was defined as the use of at least $20 \mathrm{mg}$ of prednisone (or equivalent) daily for at least two weeks, or $30 \mathrm{mg}$ daily for at least one week. Previous antimicrobial exposure within one month from the date of infection diagnosis was also examined.

Empirical antimicrobial therapy was evaluated and classified as adequate when full in vitro susceptibility was documented for at least one antimicrobial drug prescribed to the patient within $48 \mathrm{~h}$ after the culture was collected, except when false susceptibility to cephalosporins or aztreonam was observed among ESBL-producing isolates. When inadequate antimicrobial therapy was identified, the staff in charge of infection control in the facility was notified in order to permit the introduction of effective antimicrobial therapy.

Clinical outcomes evaluated were length of stay after the diagnosis of infection, crude mortality and mortality attributable to infection. Death was considered attributable to infection when it occurred within two weeks from the diagnosis of infection, in the presence of clinical and laboratory evidence of active infection, and could not be strictly related to other fatal conditions. Death was considered to be unrelated to infection when it occurred more than two weeks after the diagnosis of infection or was strictly related to other fatal conditions. Patients were followed until hospital discharge.

Our methodology was cross-sectional studying risk factors for infection and prospective cohort while evaluating clinical impact. All information was tabulated in a data base using the EPI-INFO (CDC, version 6.0) software. Data were analyzed statistically using the STATA ${ }^{\circledR}$ (version 6.0) and MINITAB ${ }^{\circledR}$ (version 14) software. Bivariate analysis was performed using the nonparametric chi-square test with Yates correction, the two-tailed Fisher exact test or the Mann-Whitney test.

Possible risk factors for ESBL-producing Klebsiella spp. infection were analyzed by a multiple logistic regression model using classical and Bayesian approaches (Fredman 1996, Bland \& Altman 1998), considering the last one the gold standard. Variables initially selected for this analysis were those which had a "p" value less or equal 0,150 , under the bivariate analysis.

Possible variables associated with death were analyzed by a multiple logistic regression model using classical and Bayesian approaches, considering the last one the gold standard. Variables included in this analysis were demographic data, most frequent underlying diseases, exposure to invasive procedures or immunosuppressive therapies, presence of bacteremia, inadequate empirical antimicrobial therapy and infection due to an ESBL-strain.

We concluded that the differences were statistically significant after bivariate analysis and the multiple logistic regression model using the classical approach when $\mathrm{p}$ $\leq 5.0 \%(\alpha=0.05)$. Using the Bayesian approach, differences were considered to be statistically significant when the $95 \%$ credible intervals did not include the number zero (Fredman 1996).

\section{RESULTS}

Microbiologic data - Of all Klebsiella spp. strains identified by the microbiology laboratory during the study period, 104 were isolated from patients who met all inclusion criteria, and ESBL production was confirmed in $45.2 \%$ (47/104) of them. Among ESBL-producers, 95.7\% (45/47) were classified as K. pneumoniae, versus $87.7 \%$ (50/57) among non-ESBL-producers $(\mathrm{p}=0.179)$. The remaining isolates of both groups (9/104) were classified as $K$. oxytoca.

Demographic data and risk factors analysis - Gender distribution was similar among patients infected with ESBL and non-ESBL strains (61.7\% versus $59.6 \%$ of males, respectively, $\mathrm{p}=0.831$ ). Median age was 33.4 years for patients in the ESBL group and 42.6 years for the non-ESBL group $(\mathrm{p}=0.087)$.

Duration of hospitalization prior to the infection was significantly longer for the ESBL group when compared to the non-ESBL group (32.5 versus 12.7 days, $\mathrm{p}<0.001)$.

The proportion of ESBL/non-ESBL strains isolated was $37.5 \%$ (9/24) among surgical patients, 41.4\% (24/58) among clinical patients, and $63.6 \%(14 / 22)$ among pediatric patients. The higher proportion identified in the pediatric setting showed a borderline statistical significance $(\mathrm{p}=$ 0.086 ). 
Table I shows the frequency of selected underlying diseases among the patients studied, and shows no differences statistically significant between patients infected with ESBL and non-ESBL strains. Table II shows the distribution of the primary site of infection among patients studied and also no differences statistically significant between the two groups were found.

Bivariate analysis of previous exposure to invasive procedures or immunosuppressive therapies as possible risk factors for ESBL-producing Klebsiella spp. infection demonstrated a statistically significant association with surgery $(\mathrm{p}=0.040)$, mechanical ventilation $(\mathrm{p}<0.001)$, central venous catheter $(\mathrm{p}<0.001)$ and total parenteral nutrition ( $p=0.004)$, as shown on Table III. Bivariate analysis of previous exposure to antimicrobial drugs as possible risk factors for ESBL-producing Klebsiella spp. infection demonstrated a statistically significant association with exposure to any antimicrobial drug $(\mathrm{p}=0.003)$, to cefepime $(p=0.013)$, quinolones $(p=0.005)$, aminoglycosides $(p<0.001)$, and vancomycin $(p=0.047)$. Exposure to third generation cephalosporins showed a borderline statistical significance $(p=0.056)$. Exposure to betalactamase inhibitor combinations had no protective effect $(\mathrm{p}=0.728)$.

\section{TABLE I}

Frequency of selected underlying diseases among hospitalized patients with infection due to extended-spectrum betalactamase (ESBL)-producing or non-ESBL-producing Klebsiella spp.

\begin{tabular}{lccc}
\hline & \multicolumn{2}{c}{ Number and (\%) of patients } & \\
\cline { 2 - 3 } Disease & ESBL & Non-ESBL & $\mathrm{p}^{a}$ \\
\hline Diabetes mellitus & $7(14.9)$ & $8(14.0)$ & 1.000 \\
AIDS & $2(4.3)$ & $5(8.8)$ & 0.453 \\
Malignancy & $19(40.4)$ & $20(35.1)$ & 0.685 \\
Collagen diseases & $1(2.1)$ & $5(8.8)$ & 0.218 \\
COPD & $5(10.6)$ & $5(8.8)$ & 0.752 \\
Chronic heart failure & $8(17.0)$ & $9(15.8)$ & 1.000 \\
Renal insufficiency & $14(29.8)$ & $15(26.3)$ & 0.827 \\
Trauma & $5(10.6)$ & $3(5.3)$ & 0.463 \\
\hline
\end{tabular}

$a$ : two-tailed Fisher's exact test; COPD: chronic obstructive pulmonary disease

\section{TABLE II}

Distribution of primary site of infection among hospitalized patients with infection due to extended-spectrum betalactamase (ESBL)-producing or non-ESBL-producing Klebsiella spp.

\begin{tabular}{lccc}
\hline & \multicolumn{3}{c}{$\begin{array}{c}\text { Number and (\%) } \\
\text { of patients }\end{array}$} \\
\cline { 2 - 3 } Primary site of infection & ESBL & Non-ESBL & $\mathrm{p}^{a}$ \\
\hline Pneumonia & $16(34.0)$ & $15(26.3)$ & 0.520 \\
Primary blood stream infection & $17(36.2)$ & $16(28.1)$ & 0.501 \\
Skin/soft tissues infection & $9(19.2)$ & $14(24.6)$ & 0.671 \\
Urinary tract infection & $3(6.4)$ & $2(3.5)$ & 0.656 \\
Intra-abdominal infection & $1(2.1)$ & $6(10.5)$ & 0.125 \\
Osteomyelitis & $0(0.0)$ & $4(7.0)$ & 0.124 \\
Endocarditis & $1(2.1)$ & $0(0.0)$ & 0.452 \\
\hline Total & 47 & 57 & - \\
\hline
\end{tabular}

$a$ : two-tailed Fisher's exact test

Multiple logistic regression under classical and Bayesian approaches to possible risk factors for ESBL-producing Klebsiella spp infection are shown in Table IV, where it is pointed out that only mechanical ventilation, central venous catheter, exposure to any antimicrobial drug, cefepime or a quinolone remained as independent risk factors. Age progression was inversely associated with ESBL-producing Klebsiella spp. infection.

Bivariate analysis of length of stay after diagnosis of infection and mortality rates versus ESBL-production may be seen in Table V. Length of stay was significant longer for patients infected with ESBL-producers $(p=0.049)$ and remained longer when deaths were excluded from the analysis $(p=0.020)$. Crude and attributable to infection fatality rates were greater for patients infected with ESBL-producers, but those differences were not statistically significant ( $\mathrm{p}=0.091$ and 0.125 , respectively).

Multiple logistic regression under classical and Bayesian approaches to possible risk factors for death among the patients studied are shown in Table VI. Mechanical ventilation and bacteremia were the only independent risk factors founded in that analysis.

TABLE III

Bivariate analysis of previous exposure to invasive procedures or immunosuppressive therapies as possible risk factors for extended-spectrum beta-lactamase (ESBL)-producing Klebsiella spp. infection

\begin{tabular}{|c|c|c|c|c|}
\hline \multirow[b]{2}{*}{ Variable } & \multicolumn{2}{|c|}{ Number and $(\%)$ of patients } & \multirow[b]{2}{*}{ Odds ratio $(95 \% \mathrm{CI})$} & \multirow[b]{2}{*}{$\mathrm{p}^{a}$} \\
\hline & ESBL & Non-ESBL & & \\
\hline Surgery & $31(66.0)$ & $25(44.0)$ & $2.5(1.0-6.0)$ & 0.040 \\
\hline Foley catheter & $25(53.2)$ & $21(36.8)$ & $1.9(0.8-4.6)$ & 0.140 \\
\hline Mechanical ventilation & $24(51.1)$ & $8(14.0)$ & $6.4(2.3-18.4)$ & $<0,001$ \\
\hline Central venous catheter & $38(80.9)$ & $21(36.8)$ & $7.2(2.7-19.9)$ & $<0,001$ \\
\hline Hemodialysis & $11(23.4)$ & $8(14.0)$ & $1.9(0.6-5.8)$ & 0.329 \\
\hline Total parenteral nutrition & $18(38.3)$ & $7(12.3)$ & $4.4(1.5-13.4)$ & 0.004 \\
\hline Use of corticosteroids & $18(38.3)$ & $16(28.1)$ & $1.6(0.6-3.9)$ & 0.369 \\
\hline Immunosuppressive therapies & $12(25.5)$ & $15(26.3)$ & $1.0(0.4-2.5)$ & 0.893 \\
\hline
\end{tabular}

$a$ : Qui-square test with Yates correction 
TABLE IV

Multiple logistic regression using classical and Bayesian approaches of possible variables associated with death among patients with Klebsiella spp. infection

\begin{tabular}{|c|c|c|c|c|}
\hline \multirow{2}{*}{$\begin{array}{l}\text { Risk factor } \\
\text { Age }\end{array}$} & \multirow{2}{*}{$\begin{array}{c}\text { Multiple } \\
\text { logistic regression } \\
\text { Odds ratio (CI 95\%) } \\
0.95(0.93-0.98)\end{array}$} & \multirow{2}{*}{$\begin{array}{c}\mathrm{p} \\
0.001\end{array}$} & \multicolumn{2}{|c|}{$\begin{array}{c}\text { Bayesian analysis } \\
95 \% \text { credible interval for the } \\
\text { logistic regression coefficients }\end{array}$} \\
\hline & & & -0.083 & -0.025 \\
\hline Mechanical ventilation & $4.70(0.95-23.20)$ & 0.058 & 0.125 & 3.514 \\
\hline Central venous catheter & $4.78(1.14-20.01)$ & 0.033 & 0.297 & 3.356 \\
\hline Immunosuppressive therapies & $0.49(0.12-1.98)$ & 0.319 & -2.355 & 0.571 \\
\hline Use of any antimicrobial drug & $6.01(1.03-35.06)$ & 0.046 & 0.261 & 4.251 \\
\hline Use of cefepime & $4.51(1.12-18.21)$ & 0.034 & 0.274 & 3.273 \\
\hline Use of a carbapenem & $0.32(0.04-2.74)$ & 0.296 & -3.794 & 0.857 \\
\hline Use of a quinolone & $25.37(1.61-398.50)$ & 0.021 & 1.151 & 7.403 \\
\hline
\end{tabular}

\section{TABLE V}

Length of stay after the diagnosis of infection, crude mortality rate, and rate attributable to infection among hospitalized patients infected with extended-spectrum beta-lactamase (ESBL)-producing or non-ESBL-producing Klebsiella spp.

\begin{tabular}{|c|c|c|c|c|}
\hline & \multicolumn{2}{|c|}{ Mean length of stay (days) } & \multicolumn{2}{|c|}{ Mortality rate } \\
\hline & All patients & Survivors & Crude no. $(\%)$ & $\begin{array}{l}\text { Attributable to } \\
\text { infection no. }(\%)\end{array}$ \\
\hline ESBL group & 25.1 & 36.0 & 26/47 (55.3) & $16 / 47(34.0)$ \\
\hline Non-ESBL group & 23.7 & 21.7 & $21 / 57(36.8)$ & $11 / 57(19.3)$ \\
\hline $\mathrm{p}$ & $0.049^{a}$ & $0.020^{a}$ & $0.091^{b}$ & $0.125^{b}$ \\
\hline
\end{tabular}

$a$ : Mann-Whitney; $b$ : chi-square Yates corrected test

TABLE VI

Multiple logistic regression using classical and Bayesian approaches of possible risk factors for death among patients with Klebsiella spp. infection

\begin{tabular}{|c|c|c|c|c|}
\hline \multirow{2}{*}{$\begin{array}{l}\text { Risk factor } \\
\text { Age }\end{array}$} & \multirow{2}{*}{$\begin{array}{c}\text { Multiple } \\
\text { logistic regression } \\
\text { Odds ratio (CI 95\%) } \\
1.0(0.9-1.0)\end{array}$} & \multirow{2}{*}{$\begin{array}{c}\mathrm{p} \\
0.981\end{array}$} & \multicolumn{2}{|c|}{$\begin{array}{c}\text { Bayesian analysis } \\
95 \% \text { credible interval for the } \\
\text { logistic regression coefficients }\end{array}$} \\
\hline & & & -0.026 & 0.025 \\
\hline Male gender & $1.9(0.6-5.8)$ & 0.235 & -0.406 & 2.019 \\
\hline Chronic heart failure & $2.7(0.5-14.3)$ & 0.249 & -0.614 & 3.044 \\
\hline Renal insufficiency & $2.7(0.7-11.0)$ & 0.157 & -0.274 & 2.760 \\
\hline COPD & $2.7(0.3-23.7)$ & 0.372 & -1.074 & 3.635 \\
\hline Malignancy & $0.7(0.2-2.2)$ & 0.563 & -1.693 & 0.902 \\
\hline AIDS & $3.5(0.5-26.5)$ & 0.221 & -0.677 & 4.011 \\
\hline Foley catheter & $1.8(0.5-7.0)$ & 0.398 & -0.809 & 2.282 \\
\hline Mechanical ventilation & $3.6(0.9-14.6)$ & 0.070 & 0.056 & 3.264 \\
\hline Central venous catheter & $0.4(1.0-1.7)$ & 0.215 & -2.646 & 0.473 \\
\hline Hemodialysis & $1.9(0.4-10.0)$ & 0.427 & -0.924 & 2.735 \\
\hline Surgery & $0.4(0.1-1.3)$ & 0.132 & -2.580 & 0.143 \\
\hline Use of corticosteroids & $1.2(0.4-3.4)$ & 0.747 & -0.914 & 1.377 \\
\hline Bacteremia & $4.5(1.2-17.5)$ & 0.028 & 0.436 & 3.459 \\
\hline ESBL-producing strain & $2.3(0.7-7.5)$ & 0.249 & -0.543 & 2.521 \\
\hline Inadequate empirical therapy & $1.0(0.2-3.4)$ & 0.970 & -1.358 & 1.276 \\
\hline
\end{tabular}

COPD: chronic obstructive pulmonary disease

\section{DISCUSSION}

In the current study, $45.2 \%$ of Klebsiella spp. infections were caused by an ESBL-producing strain, a rate that can be considered high compared to some NorthAmerican or European studies, where it has been demonstrated rates below 25\% (Itokazu et al. 1996, CDC 1998, Calatayud et al. 2005), but is very similar to those de- scribed for Latin America (Sader et al. 1999, Saka et al. 2003, Lupi et al. 2004).

The frequency of selected underlying diseases and primary site of infection were closely similar for patients infected with an ESBL or a non-ESBL strain, a fact that permitted us to analyse the risk factors and clinical impact associated with ESBL production.

Young age was identified as a risk factor for ESBL- 
producing infection. Knowing that a higher ESBL/nonESBL infection proportion was detected among pediatric patients, we speculate if this could be related to a high rate of cross-transmission in the pediatric setting, although others have reported a similar finding (Rebuck et al. 2000).

Among invasive procedures, mechanical ventilation and central venous catheter were both associated with an ESBL-producing infection, which is in agreement with other studies (Piroth et al. 1998, Rebuck et al. 2000, Lautenbach et al. 2001, Menashe et al. 2001). How invasive procedures lead to this risk is still not completely elucidated, but it is notorious that patients submitted to them are at a greater risk for infectious complications of any etiology (Martone 1991). This leads to antimicrobial prescription, which in turn may select ESBL-producing strains. Also, these procedures demand more intensive care from health-care professionals, creating opportunities for cross-transmission of resistant bacteria (Weinstein 1991).

Antimicrobial exposure, as described by many others (Kim et al. 2002, Lee et al. 2004, Schwaber et al. 2004), was implicated as an important risk factor for ESBL-producing infection. It is interesting to note that exposure to thirdgeneration cephalosporins was not implicated as a risk factor in the logistic regression model, a result that may be explained by the fact that, recently, cefepime has been frequently used at the study hospital in opportunities where formerly ceftriaxone or ceftazidime were used. Thus, it is possible that low exposure to the latter drugs masked their risk effect, extensively demonstrated in the literature (Lautenbach et al. 2001, Kim et al. 2002, Lee et al. 2004). Unfortunately, the use of cefepime was also incriminated as a risk factor in the present series, a fact that, to our knowledge, had not been described before. Exposure to aminoglycosides or vancomycin was also implicated as a risk factor in the bivariate analysis but not in the logistic regression model. In the first case, a possible explanation is that it is usual at the study facility to prescribe aminoglycosides along with cephalosporins in order to achieve a synergic antimicrobial effect. The use of vancomycin may be a confounder linked to the fact that ESBL infections frequently are of nosocomial origin, a fact that leads to the empirical prescription of vancomycin before etiologic identification (Paterson 2002).

Length of stay was significantly superior among patients in the ESBL group (Stone et al. 2003, Lupi et al. 2004), an event possibly related to the fact that, at the time when the microbiologic results become available, patients infected with non-ESBL strains frequently have had two or three days of effective empirical therapy. This is not always the case for patients with an ESBL-producing strain since these strains are mostly resistant to various antimicrobial drugs (Lautenbach et al. 2001). In addition, non-ESBL strains are more likely to be susceptible to available oral drugs, favoring early patient discharge.

ESBL production was not associated with a higher risk of death in the present study. The literature is conflictive about this effect. Kim et al. (2002), Bermejo et al. (2003), and Lupi et al. (2004) reported a higher mortality rate among patients infected with an ESBL-producing $K$. pneumoniae, compared to those infected by non-ESBL-producing strains, but they did not use multivariate analysis. In contrast, Menashe et al. (2001) and Kang et al. (2004), analyzing bloodstream infections caused by ESBL-producing and non-ESBL-producing Enterobacteriaceae, found a similar mortality rate for the two groups. It is noteworthy that adequate empirical therapy was not associated with a reduced risk of death in the present study, just as found by Martínez et al. (2005).

In fact, bacteremia and mechanical ventilation were the only variables independently associated with fatal outcome. They are both related to the severity of illness, which appears to be far more relevant than ESBL production as a predictor of death among hospitalized patients with Klebsiella spp. infection.

The present study has at least three limitations. First, cross-sectional analysis of risk factors for infection caused by antibiotic-resistant microorganisms may overestimate the role of antimicrobial exposure, as demonstrated by Paterson (2002) and Harris et al. (2002). Second, risk factors for colonization, such as inadequate infection control practices, may also pose a risk for infection due to ESBL-producing strains, and were not assessed in our study. And third, adjuvant treatments, such as central venous catheter removal or abscess drainage, may influence outcomes, but were not included in the present analysis.

Finally, it should be pointed out that differences in terms of bacterial species involved, kind of ESBL produced, site of infection, and methodology do not permit a full comparison of the present investigation with the referred studies.

\section{ACKNOWLEDGEMENT}

To Rosa Helena Amprino Romanella Gironi, Lucélia Aparecida Pereira, and Sohaila Mohamed Kassin Hussain for the assistance to this research on the microbiology laboratory.

\section{REFERENCES}

Archibald LK 2004. Gram-negative, hospital-acquired infections: a growing problem. Infect Control Hosp Epidemiol 25: 809-811.

Bermejo J, Lesnaberes P, Arnesi N, Gianello M, Notario R, Borda N, Gambande T, Bencomo B 2003. Factores de riesgo asociados a infecciones por Klebsiella pneumoniae. Enferm Infecc Microbiol Clin 21: 72-76.

Bland JM, Altman DG 1998. Statistics notes: Bayesians and frequentists. Br Med J 317: 1151

Bratu S, Mooty M, Nichani S, Landman D, Gullans C, Pettinato B, Karumudi P, Tolaney P, Quale J 2005. Emergence of KPC-possesing Klebsiella pneumoniae in Brooklyn, New York: epidemiology and recommendations for detection. Antimicrob Agents Chemother 49: 3018-3020.

Calatayud L, Dominguez C, Ardanuy F, Tubau M, Argerich J, Liñares C, Peña M, Pujol R, Martín R 2005. Simultaneous colonization by different species of extended-spectrum betalactamases producing Enterobacteriaceae (ESBL-EB) in ICU patients. Abstracts of the 45th Interscience Conference on Antimicrobial Agents and Chemotherapy, American Society for Microbiology, Washington, DC, p. 331.

CDC-Centers for Disease Control and Prevention. 1998. National nosocomial infections surveillance system antimi- 
crobial resistance surveillance report [on line] http:// www.cdc.gov/ncidod/hip/NNIS/AR_Surv1198.htm. Accessed 25 April 2004.

Chanawong A, M'zali FH, Heritage J, Lulitanond A, Hawkey PM 2001. SHV-12, SHV-5, SHV-2a and VEB-1 extendedspectrum beta-lactamases in Gram-negative bacteria isolated in a university hospital in Thailand. J Antimicrob Chemother 48: 839-852.

Cofsky R, Vangala K, Haag R, Recco R, Maccario E, Sathe S, Landman D, Mayorga D, Burgonio B, Sepkowitz D, Chapnick E, Hinedi T, Adedeji A, Quale J 2002. The cost of antibiotic resistance: effect of resistance among Staphylococcus aureus, Klebsiella pneumoniae, Acinetobacter baumannii, and Pseudomonas aeruginosa on length of hospital stay. Infect Control Hosp Epidemiol 23: 106-108.

Fredman, L. 1996. Bayesian statistical methods. Br Med J 313: 569-570.

Garner JS, Jarvis WR, Emori TG, Horau TC, Hughes JM 1988. CDC definitions for nosocomial infections, 1988. Am J Infect Control 16: 128-140.

Harris AD, Samore MH, Lipsitch M, Kaye KS, Perencevich E, Carmeli Y 2002. Control-group selection importance in studies of antimicrobial resistance: examples applied to Pseudomonas aeruginosa, Enterococci, and Escherichia coli. Clin Infect Dis 34: 1558-1563.

Itokazu GS, Quinn JP, Kahan FM 1996. Antimicrobial resistance rates among aerobic Gram-negative bacilli recovered from patients in intensive care units: evaluation of national postmarketing surveillance program. Clin Infect Dis 23: 779784.

Kang C, Kim S, Kim DM, Park WB, Lee KD, Kim HB, Oh M, Kim EC, Choe K 2004. Risk factors for and clinical outcomes of bloodstream infections caused by extended-spectrum beta-lactamase-producing Klebsiella pneumoniae. Infect Control Hosp Epidemiol 25: 860-867.

Kim YK, Pai H, Lee HJ, Park SE, Choi EH, Kim J, Kim JH, Kim EC 2002. Bloodstream infections by extended-spectrum beta-lactamase-producing Escherichia coli and Klebsiella pneumoniae in children: epidemiology and clinical outcome. Antimicrob Agents Chemother 46: 1481-91.

Knothe H, Shah P, Kremery V, Antal M, Mitsuhashi S 1983. Transferable resistance to cefotaxime, cefoxitin, cefamandole and cefuroxime in clinical isolates of Klebsiella pneumoniae and S. marcescens. Infection 11: 315-317.

Lautenbach E, Patel JB, Bilker WB, Edelstein PH, Fishman NO 2001. Extended-spectrum beta-lactamase-producing Escherichia coli and Klebsiella pneumoniae: risk factors for infection and impact of resistance on outcomes. Clin Infect Dis 32: 1162-1171.

Lee S, Lee ES, Park SY, Kim S, Seo Y, Cho YK 2004. Reduced use of third-generation cephalosporins decreases the acquisition of extended-spectrum beta-lactamase-producing Klebsiella pneumoniae. Infect Control Hosp Epidemiol 25: 832837.

Lupi O, Campos T, Faria E, Kalab L, Pereira B, Brazil P 2004. Epidemiology of multiresistant $K$. pneumoniae cases using Serial Temporal Models. Int J Antimicrob Agents 24 (Suppl. II): 145-146.

Martínez JA, Almela M, Marco F, López F, Soriano A, Mensa
J 2005. Prognostic Factors of Escherichia coli, Klebsiella spp and Proteus mirabilis Bacteremia in the Era of Extended-Spectrum B-lactamase Producing Organisms (ESBL). Abstracts of the 45th Interscience Conference on Antimicrobial Agents and Chemotherapy, American Society for Microbiology, Washington, DC, p. 332.

Martins IS, Lopes GS, Santos IC, Riley LW, Moreira BM 2005. An outbreak of Extended-Spectrum B-lactamase (ESBL)Producing Klebsiella pneumoniae Infection Among Renal Transplant Patients. In Abstracts of the 45th Interscience Conference on Antimicrobial Agents and Chemotherapy, American Society for Microbiology, Washington, DC, p. 330.

Martone WJ 1991. Year 2000 objectives for preventing nosocomial infections: how do we get there? Am J Med 91: 3943.

Menashe G, Borer A, Yagupsky P, Peled N, Gilad J, Fraser D, Riesenberg K, Schlaefer F 2001. Clinical significance and impact on mortality of extended-spectrum beta lactamaseproducing Enterobacteriaceae isolates in nosocomial bacteremia. Scand J Infect Dis 33: 188-193.

M'zali FH, Chanawong A, Kerr KG, Birkenhead D, Hawkey PM 2000. Detection of extended-spectrum beta-lactamases in members of the family Enterobacteriaceae: comparison of the MAST DD test, the double disc and the E-test ESBL. $J$ Antimicrob Chemother 45: 881-885.

NCCLS-National Committee for Clinical Laboratory Standards. 2000. Performance Standards for Antimicrobial Disk Susceptibility Tests, 7th ed., Wayne, PA.

Naumovski L, Quinn JP, Miyashiro D, Patel M, Bush K, Singer SB, Graves D, Palskill T, Arwin AM 1992. Outbreak of ceftazidime resistance due to a novel extended-spectrum beta-lactamase in isolates from cancer patients. Antimicrob Agents Chemother 36: 1991-1996.

Paterson DL, Ko WC, Mohapatra S 1997. Klebsiella pneumoniae bacteremia: impact of extended-spectrum $\beta$-lactamase (ESBL) production in a global study of 216 patients. In Program and Abstracts of the 37th Interscience Conference on Antimicrobial Agents and Chemotherapy, American Society for Microbiology, Washington, DC.

Paterson DL 2002. Looking for risk factors for the acquisition of antibiotic resistance: a 21 st-century approach. Clin Infect Dis 34: 1564-1567.

Petroni A, Corso A, Melano R, Cacace ML, Bru AM, Rossi A, Galas M 2002. Plasmidic extended-spectrum betalactamases in Vibrio Cholerae O1 El Tor isolates in Argentina. Antimicrob Agents Chemother 46: 1462-1468.

Piroth L, Aubé H, Doise JM, Vincent-Martin M 1998. Spread of extended-spectrum b-lactamase-producing Klebsiella pneumoniae: are $\beta$-lactamase inhibitors of therapeutic value? Clin Infect Dis 27: 76-80.

Poirel L, Menuteau O, Agoli N, Cattoen C, Nordmann P 2003. Outbreak of extended-spectrum $\beta$-lactamase VEB-1-producing isolates of Acinetobacter baumannii in a French hospital. J Clin Microbiol 41: 3542-3547.

Quinteros M, Radice M, Gardella N, Rodriguez MM, Costa N, Korbenfeld D, Couto E, Gutkind G 2003. Extended-spectrum $\beta$-lactamases in Enterobacteriaceae in Buenos Aires, Argentina, public hospitals. Antimicrob. Agents Chemother 47: 2864-2867. 
Rebuck JA, Olsen KM, Fey PD, Langnas NA, Rupp ME 2000. Characterization of an outbreak due to extended-spectrum $\beta$-lactamase-producing Klebsiella pneumoniae in a pediatric intensive care unit transplant population. Clin Infect Dis 31: 1368-1372.

Sader HS, Sampaio JL, Zoccoli C, Jones RN 1999. Results of the 1997 SENTRY antimicrobial surveillance program in three Brazilian medical centers. Braz J Infect Dis 3: 63-79.

Saka HA, Egea M, Culasso C, Rollan R, Avaro A, Carvajal L 2003. b-lactamasas de espectro extendido en Klebsiella pneumoniae aisladas en el hospital de niños de Córdoba, Argentina. Rev Argent Microbiol 35: 1-7.
Schwaber MJ, Cosgrove SE, Gold HS, Kaye KS, Carmeli Y 2004. Fluorquinolones protective against cephalosporin resistance in Gram-negative nosocomial pathogens. Emerg Infect Dis 10: 94-99.

Stone P, Gupta A, Loughrey M, Della-Latta P, Cimiotti J, Larson E, Rubenstein D, Saiman L 2003. Attributable costs and length of stay of an extended-spectrum beta-lactamase-producing Klebsiella pneumoniae outbreak in a neonatal intensive care unit. Infect Control Hosp Epidemiol 24: 601-606.

Weinstein RA 1991. Epidemiology and control of nosocomial infections in adult intensive care units. Am J Med 91: 179184. 